


\title{
Penn World Table 7.0: Are the Data Flawed?
}

\author{
Theodore R. Breton* \\ Universidad EAFIT
}

May 8, 2012

\begin{abstract}
PWT 7.0 data deviate substantially from PWT 6.3 data because the benchmarked prices for 1970 to 1996 used in PWT 6.3 were entirely discarded. PWT 7.0 data are unreliable and appear to be much less accurate than PWT 6.3 data.
\end{abstract}

JEL Code: E01, O47

Key Words: $\quad$ Price Indices; Economic Data; Data Measurement; Economic Growth

*Theodore R. Breton, Universidad EAFIT, Carrera 49\#7 Sur-50, avenida Las Vegas, Medellin, Colombia, 574-261-9334, 574-261-9294 (fax), tbreton@eafit.edu.co 


\section{Introduction}

The Penn World Table (PWT) is a multi-country set of data that measure economic activity over time using a uniform set of prices for goods and services across countries. These prices are based on surveys undertaken in 1970, 1975, 1980, 1985, 1990, 1996, 2002, and 2005. PWT 6.3 utilizes the benchmarked prices through 2002. PWT 7.0 utilizes the more comprehensive benchmarked data collected in International Comparison Program (ICP) 2005. In theory the data in PWT 6.3 and PWT 7.0 should be similar for all countries from 1950 to 1996 and for some countries from 1996 to 2002. But an examination of these data shows that they differ substantially for the entire period 1950 to 2007. Two questions immediately arise: Are the data in PWT 7.0 an improvement over the data in PWT 6.3? And more importantly, are the data in either version reliable?

Johnson, Larson, Papageorgiou, and Subramanian [2009] evaluated the methodology used to create the economic data in PWT 6.1 and 6.2. They determined that the data in these versions of the PWT are based primarily on the most recent benchmarked prices and do not correctly incorporate earlier benchmarked prices.

Based on a review of the documentation and an analysis of data from the last five versions of the PWT, I conclude that the data in PWT 6.3 and 7.0 were created using a similar methodology. I also conclude that the PWT 7.0 data are unreliable and much less accurate than the PWT 6.3 data because they are based entirely on ICP 2005 prices, which are dramatically different from earlier benchmarked prices. In the rest of this paper I present data from various versions of the PWT and analyses of these data that support these conclusions.

\section{GDP/capita and Price Indices: PWT 7.0 vs. PWT 6.3}


Figure 1 presents GDP/capita data from the rgdpch series for 1950 to 2007 from PWT 6.3 and PWT 7.0 for the UK and the Philippines. Since these two countries participated in all the price benchmarking studies [Heston, Summers, and Aten, 2008], their data should be among the most reliable for high and low income countries. Since the economic data in PWT 6.3 and PWT 7.0 between 1950 and 1996 are based in theory on prices obtained from benchmarking studies during this period and on the same data from the National Accounts, these data should be similar. Instead Figure 1 shows that from 1950 to 2007 GDP/capita in the UK is consistently higher in PWT 7.0 than in PWT 6.3. In the Philippines GDP/capita in PWT 7.0 is consistently about $40 \%$ lower than in PWT 6.3, even during the 1950 to 1996 period. How could this happen?

\section{Figure 1}

\section{GDP/capita in Benchmarked Countries}

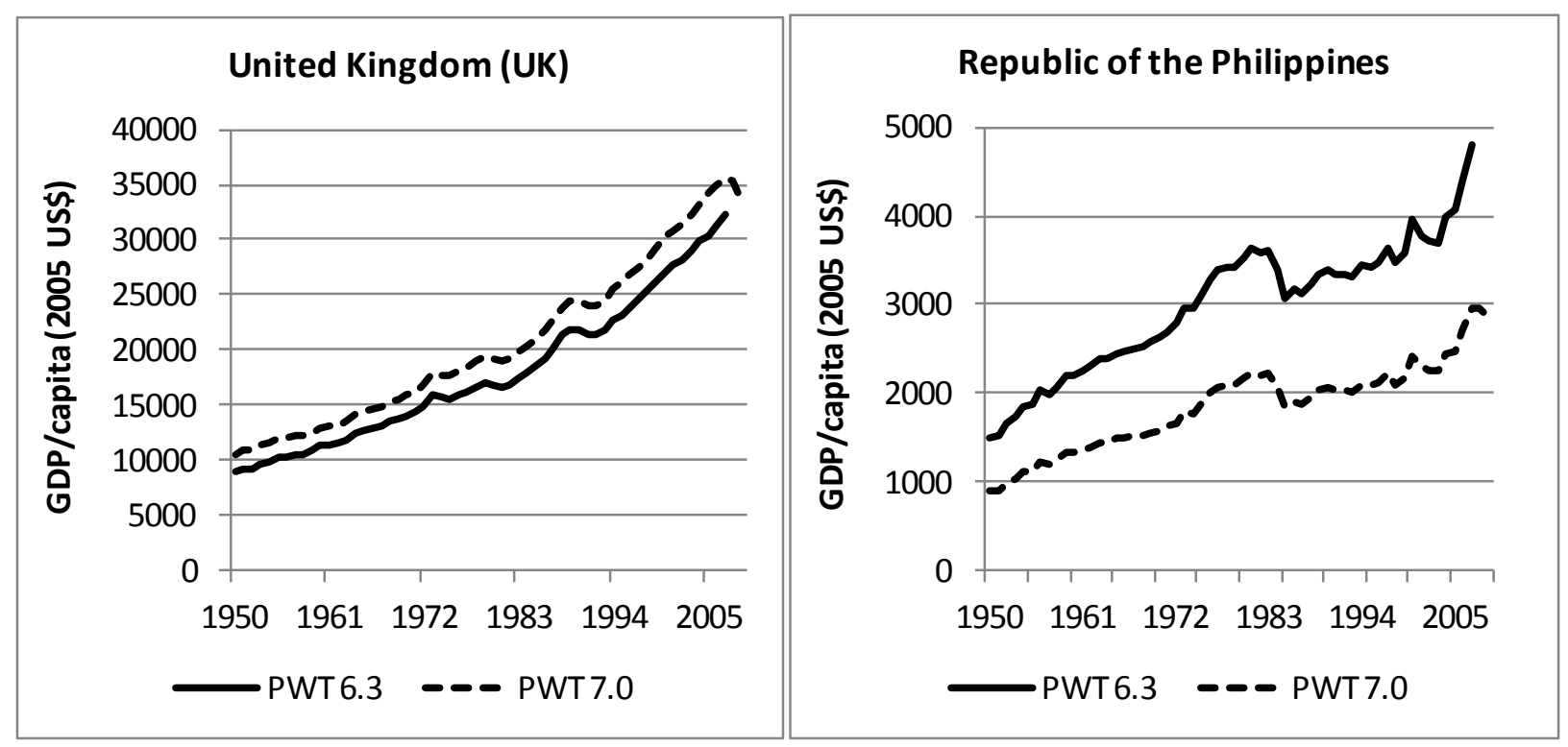

The documentation for PWT 7.0 does not provide any explanation for these dramatic changes in the historic data, so presumably the methodology used to create the data in PWT 7.0 is similar to that used in earlier versions. Johnson, et. al. [2009] reviewed the methodology used 
to create PWT 6.1 and 6.2. They observe that the economic data in each generation of PWT is created by specifying a set of prices for the latest benchmarked year, using these prices to adjust the economic data in each country's National Accounts in this year, and then projecting this adjusted data backward and forward using the growth rates in the unadjusted National Accounts data.

The pattern of changes in the GDP/capita data between PWT 6.3 and 7.0 is consistent with this methodology. The changes in relative prices in ICP 2005 would change PWT 6.3's estimates of GDP/capita in 2005 and then the National Accounts data would create a similar growth projection backward to 1950 in both data sets. Neither set of data would be valid except in the benchmarked year, which would be 1996 (or 2002) for PWT 6.3 and 2005 for PWT 7.0. With this approach the economic data prior to the recent benchmarked year would be more or less biased in each version of the PWT depending on how much the most recent benchmarked prices diverge from earlier benchmarked prices. So did large changes in the benchmarked prices in PWT 7.0 cause the large changes in the estimates of GDP/capita?

Each version of the PWT provides annual price indices for investment (pi) and for GDP (p) for all countries. Figure 2 shows the ratio pi/p in 1996 in PWT 6.3 and in PWT 7.0 for the same 61 countries. In PWT 6.3 this ratio varies substantially across countries by level of income. It is 2-3 times higher in low-income countries than in high-income countries. This pattern is consistent with earlier versions of the PWT, in which investment goods in low-income countries had higher average prices than goods in other sectors of the economy [Summers and Heston, 1991].

In stark contrast, in PWT 7.0 the ratio pi/p in 1996 is invariant across countries. Evidently, PWT 7.0 did not use PWT 6.3's price indices for 1996. I confirm this in Table 1, 
which presents the results for a series of regressions using PWT data for 187 countries. The results show that PWT 7.0's ratio of relative prices in 1996 is highly correlated with its ratio of relative prices in 2005 and is not correlated with PWT 6.3's ratio of relative prices in 1996.

These results indicate that in PWT 7.0 the relative prices from earlier benchmarked prices were entirely discarded.

\section{Figure 2}

\section{Ratio of the Price Indices pi/p Across Countries in 1996}
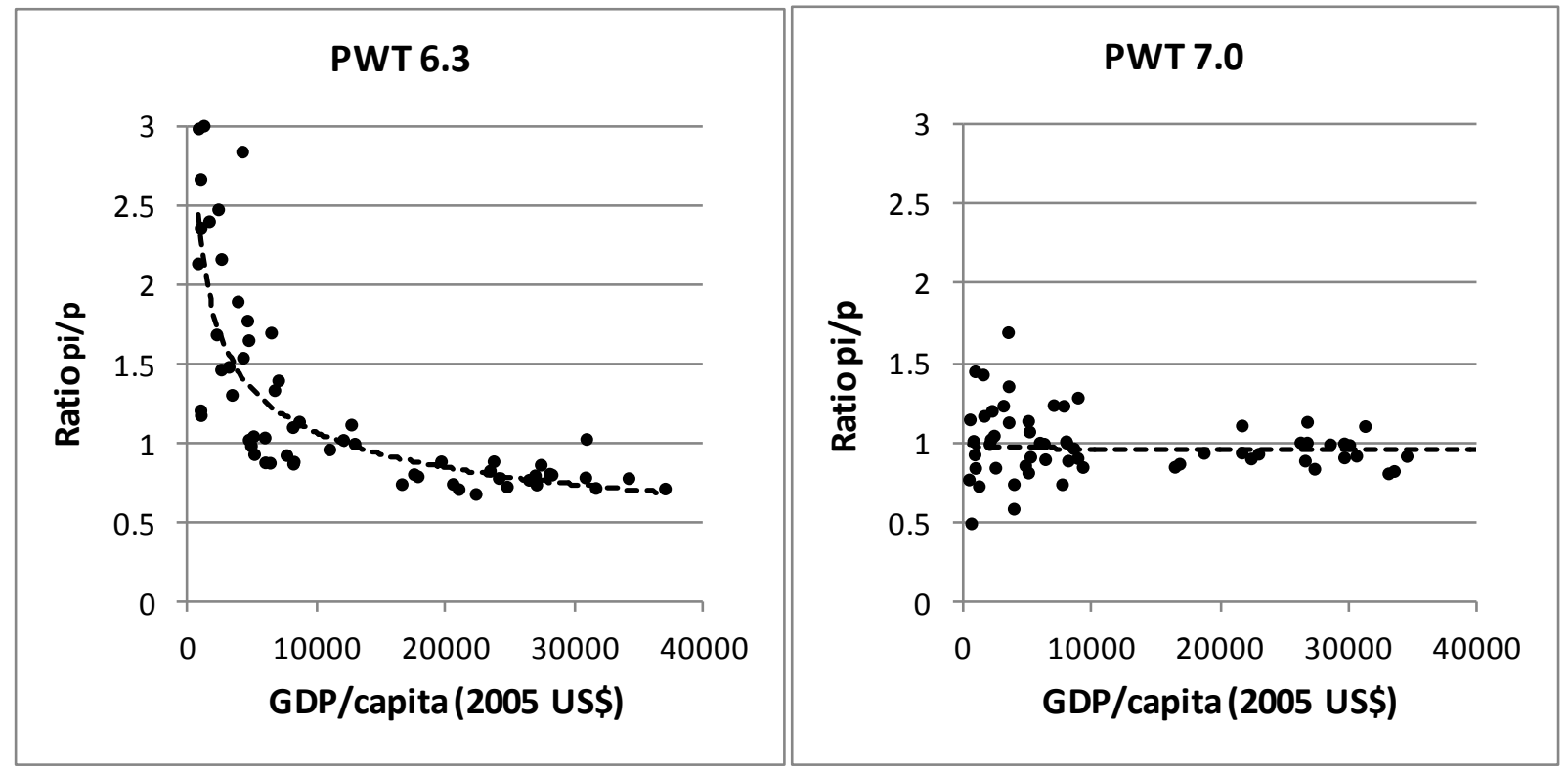

\section{Reliability of the Data in PWT 6.3 and PWT 7.0}

Johnson, et. al. [2009] demonstrate that the historic economic data in PWT 6.1 and 6.2 are inconsistent, even though both versions are based on relative prices in 1996. Clearly the economic data in PWT 6.3 and 7.0 are far more inconsistent, since they are based on benchmarked prices for different years and, as shown in Figure 2, these prices are dramatically different. 


\begin{tabular}{|l|c|c|c|c|c|}
\hline \multicolumn{7}{|c|}{ Table 1 } \\
\multicolumn{7}{|c|}{$\begin{array}{l}\text { Relationship of Ratio pi/p in PWT 7.0 in 1996 to Other pi/p Ratios } \\
\text { (Dependent variable is pi/p) }\end{array}$} \\
\hline Observations & 187 & 187 & 187 & 187 & 187 \\
\hline PWT 6.3 - Year 1996 & 0.20 & & 0.04 & 0.03 & \\
& $(.09)$ & & $(.04)$ & $(.04)$ & \\
\hline PWT 7.0 - Year 2005 & & 1.10 & 1.06 & 1.00 & 1.04 \\
& & $(.11)$ & $(.11)$ & $(.04)$ & $(.03)$ \\
\hline Constant & 0.80 & -0.06 & -0.08 & & \\
& $(.10)$ & $(.10)$ & $(.11)$ & & \\
\hline $\mathbf{R}^{\mathbf{2}}$ & 0.08 & 0.41 & 0.41 & 0.88 & 0.88 \\
\hline
\end{tabular}

The creators of the PWT data were concerned that a methodology based on the latest set of benchmarked prices could substantially alter the historic data in each version of the PWT, so they implemented a "consistentizacion" procedure in PWT 5.6 and PWT 6.1 to reduce the magnitude of these changes [Heston, Summers, and Aten, 2008]. The economic data in PWT 6.1 were created from a set of relative prices in 1996 that when possible were based 2/3 on benchmarked prices in 1996 and 1/3 on the prices for 1985 in PWT 5.6. The prices for 1985 are essentially an average of benchmarked prices in 1970, 1975, 1980, 1985, and 1990.

The regression results in Table 1 indicate that the prices in 1996 in PWT 7.0 are based on benchmarked prices in 2005. Implicitly, in PWT 7.0 the "consistentization" process employed previously to prevent large changes in historic economic data was discontinued. The data in Figure 2 show that the prices in ICP 2005 diverge dramatically from earlier benchmarking studies. The net effect is the dramatic change in the historic economic data shown in the Philippines in Figure 1.

The economic data in PWT 5.6 are based on benchmarked prices from 1970 to 1990 , while the economic data in PWT 6.1 are based on these prices and on benchmarked prices in 1996. So a simple test of the reliability of the historic economic data in PWT 6.3 and 7.0 is the consistency of the ratios pi/p in PWT 6.3 and 7.0 with these ratios in PWT 5.6 and 6.1 over the 
1970 to 1996 period. The data in Figures 1 and 2 indicate that the potential inconsistency in the economic data is concentrated in the low-income countries.

Since the Philippines participated in all the price benchmarking studies, the price ratios in the Philippines can be used for this test. Figure 3 shows the ratios pi/p for PWT 5.6, 6.2, 6.3, and 7.0 for the Philippines for 1950 to 2009, calculated from the price indices in Heston, Summers, and Aten [2011, 2009, 2006, undated]. The ratios for PWT 6.1 are not shown since they are similar to PWT 6.2. Implicitly the "consistentization" process used in PWT 6.1 was also used in PWT 6.2.

Figure 3

Ratio pi/p for the Philippines in Different Versions of the Penn World Table

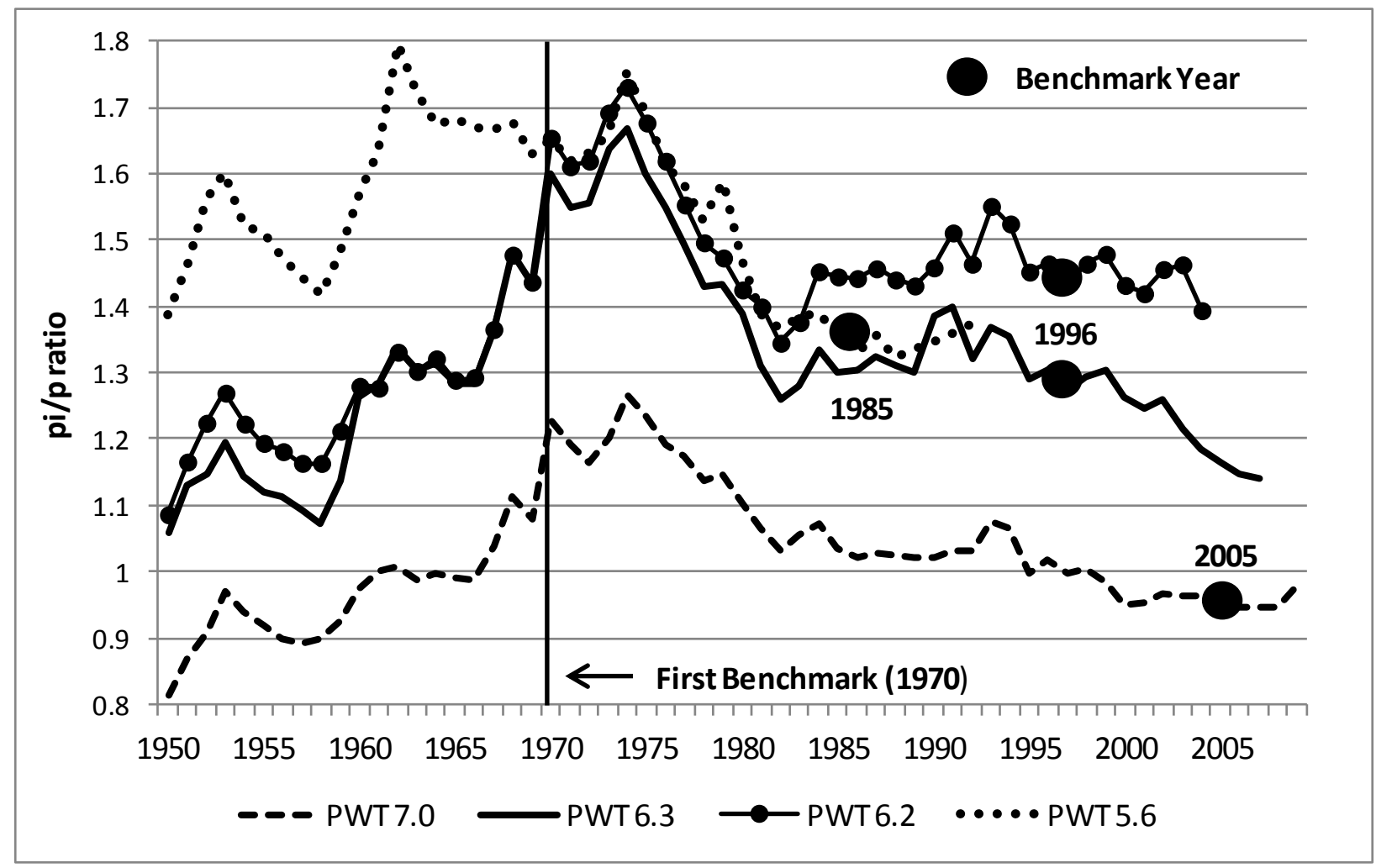


The ratios pi/p are relatively consistent in PWT 5.6, 6.2, and 6.3 over the period 1970 to 1985. These ratios are noticeably lower in PWT 6.3 than in PWT 6.2 after 1985 and are substantially lower in 1996, even though 1996 was the reference year for both. Implicitly the “consistentization" process used to create PWT 6.2 was changed or abandoned in PWT 6.3.

While it is not clear how the 1996 prices were created for PWT 6.3, the consistency of the ratios pi/p between PWT 5.6 and PWT 6.3 indicate that the economic data in PWT 6.3 are relatively consistent with benchmarked prices for the period 1970 to 1996 . In contrast, the ratios pi/p in PWT 7.0 during this period are dramatically lower than the ratios in PWT 5.6, 6.2, and 6.3. This inconsistency indicates that the economic data in PWT 7.0 from 1950 to 1996 are unreliable because they are based on benchmarked prices that are inappropriate for that period.

\section{Conclusions}

PWT economic data are created by adjusting National Accounts data using a single uniform set of prices. This methodology is unreliable because it only produces accurate data if prices do not change over time. The prices in ICP 2005 are very different from earlier benchmarked prices, so when these prices were used to create the data in PWT 7.0, they produced inaccurate data for the period from 1950 to 1996. 


\section{REFERENCES}

Heston, Alan, Summers, Robert, and Aten, Bettina, 2011, Penn World Table Version 7.0, Center for International Comparisons of Production, Income and Prices at the University of Pennsylvania, May 2011

Heston, Alan, Summers, Robert, and Aten, Bettina, 2009, Penn World Table Version 6.3, Center for International Comparisons of Production, Income and Prices at the University of Pennsylvania, August 2009

Heston, Alan, Summers, Robert, and Aten, Bettina, 2008, "What is Different, What is New?

Data Appendix for a Space-Time System of National Accounts: Penn World Table 6.1 (PWT 6.1)," Last revised 2/14/08

Heston, Alan, Summers, Robert, and Aten, Bettina, 2006, Penn World Table Version 6.2, Center for International Comparisons of Production, Income and Prices at the University of Pennsylvania, September 2006

Heston, Alan, Summers, Robert, and Aten, Bettina, undated, Penn World Table 5.6, Center for International Comparisons of Production, Income and Prices at the University of Pennsylvania Johnson, Simon, Larson, William, Papageorgiou, Chris, and Subramanian, Arvind, 2009, "Is Newer Better? Penn World Table Revisions and Their Impact on Growth Estimates," NBER, Working Paper 15455

Summers, Robert, and Heston, Alan, 1991, "The Penn World Table (Mark 5): An Expanded Set of International Comparisons, 1950-1988," Quarterly Journal of Economics, v106, n2, 327-368 